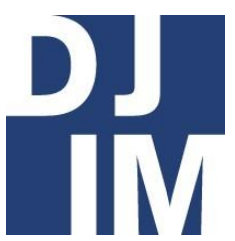

Volume 14

Spring

2018

djim.management.dal.ca |

\title{
Building for Diversity: How Public Libraries Can Create Great Multilingual Collections
}

Jen Hill

School of Information Management, Dalhousie University

\begin{abstract}
In a multicultural and multilingual country like Canada, building quality multilingual collections in public libraries is an important part of providing equitable library service to all community members. However, this can pose a challenge especially for smaller library systems or systems where no staff speak major community languages. Having multilingual staff offers a significant advantage, both in terms of making connections with community members and being able to appropriately select and catalogue materials. Libraries, MLIS programs, and Library Technician programs should therefore encourage applications from diverse candidates. Even without multilingual staff, however, libraries can be successful in creating appropriate multilingual collections by following a process that includes community consultation, collaborating with other libraries to share information, identifying good vendors, cataloguing and maintaining the collection, marketing it appropriately, and providing staff training. Through this process, a library can get to know the needs of its community, build relationships and gain experience creating and maintaining a quality multilingual collection. A multilingual collection and other services like cultural programming can mutually support each other through advertising to participants. Although it can be challenging, successfully engaging and serving a diverse community is rewarding and will be appreciated.
\end{abstract}

\section{Introduction}

Public libraries in Canadian communities face the challenge of serving the information needs of diverse populations.

They desire to be welcoming to all users; however, diversity can make designing collections and services more challenging 
(Baker, 2012). In larger cities, there can be many different small and large language communities. The size and balance of language communities can vary greatly from region to region (Lynch, 2015). They can be made up of mainly newcomers, who may also be learning English. They can also be made up of long-time Canadians who are interested in maintaining their nonEnglish language skills, either in their first language or in a language they have learned (Atlestam, Brunnstrm, \& Myhre, 2011). Like other library users, minority language speakers have different preferences, interests, and information needs. While there are many aspects to providing quality public library service to a diverse, multilingual population, an important part is maintaining a quality multilingual collection (Dilevko \& Dali, 2002).

Building and supporting an appropriate multilingual collection for a community's population can be challenging, especially if no library staff speak the major languages spoken in the community. However, working to get to know the community and their needs, collaborating with other libraries, identifying good vendors, working to maintain and market the collection, and providing staff training can help a library overcome the challenge and serve their diverse population well. One library in Sweden, Gothenburg City Libraries, provides an excellent example of consultation and engagement of its multilingual users, which helped them to identify collection gaps.

\section{Discussion}

The Value of Multilingual Collections

People unfamiliar with multilingual collections may ask why they are important in public libraries. They are important because public libraries are tasked with providing appropriate and relevant content and promoting reading for all users (Atlestam et al., 2011). Multilingual collections are an option that library users can access for information as well as pleasure reading. Serving all the residents of a community is a matter of both law and tradition for public libraries (Steckman, 1998). The American Library Association's (ALA) Reference and User Services Association (RUSA) viewed this as important enough to set out guidelines for the Development and Promotion of Multilingual Collections and Services (RUSA, 2007). They stated that it "is the responsibility of libraries to provide an equitable level of service to all members of their communities regardless of ethnic, cultural or linguistic background." It "should not be seen as an 'additional' or 'extra' service, but as an integral part of every library's service" (RUSA, 2007, p. 198). In Canada, the National Library's publication, $A$ World of Information, encourages public libraries across Canada to set up and manage multilingual collections (Dilevko \& Dali, 2002). It advocates for multilingual service on a fair and equitable per capita level (Dilevko \& Dali, 2002). Newcomers that participated in a focus group said that they feel respected Building for Diversity 
and confirmed by finding literature in their native language at the public library (Atlestam et al., 2011). It gives them pride in their culture of origin (Atlestam et al., 2011). It helps create the sense of welcoming and inclusivity that libraries desire.

\section{What Multilingual Collections Contain}

Some public libraries call their collection a multilingual collection, such as Halifax Public Libraries. Others, such as Greater Victoria Public Libraries, call their collection a world languages collection (Greater Victoria Public Library, 2017). Some multibranch library systems, such as Victoria, Toronto Public Library, and Vancouver Public Library have chosen to divide their collection and house certain languages at certain branches. The languages collected generally represent the demographics of the neighbourhoods (Toronto Public Library, 2017; Vancouver Public Library, 2017). Based on the number of branches holding materials, Chinese and French materials seem to be the most popular in Vancouver, then Vietnamese and Tagalog (Vancouver Public Library, 2017). In Toronto, Chinese, French, Hindi, and Spanish are housed at the most branches (Toronto Public Library, 2017). Absent from these world languages lists or collections are Indigenous languages. Indigenous languages seem to be little discussed in journal articles about multilingual collections or services, which instead focus on languages that are generally from other countries, and sometimes includes French. Indigenous languages potentially may be collected elsewhere by these library systems, but some similar considerations about appropriate representation and building their collections would apply. There are at least 53 different Indigenous languages in Canada (Skrzeszewski, 1993). Many are primarily oral languages and could potentially have limited available print resources (Skrzeszewski, 1993). This paper will follow the trend of the research articles and not include discussion of Indigenous languages, but there would likely be many similarities about building collections in these languages.

\section{Creating Multilingual Collections is a Multistep Process}

Creating or improving a multilingual or world languages collection is a multistep process that takes time. Steps include finding out the demographics and makeup of the community, determining their needs and interests, deciding what level of service the library can provide, sourcing the material, cataloguing and maintaining it, marketing the collection, and providing staff training. These steps will need to be repeated, updating and evaluating the collection periodically to ensure that it is still meeting the community's needs. The community's make-up and needs could change over time and should be periodically re-evaluated (RUSA, 2007). 


\section{Creating a Multilingual Collection begins with Demographics}

The process of creating a multilingual collection should begin with understanding the community's demographics. Libraries should strive to provide an effective, balanced, and substantial collection for each community language group (RUSA, 2007). Community analyses and statistical data can provide base information for material selection (RUSA, 2007), which can indicate the relative size of each language community. If there is an existing multilingual collection, demographic information could be compared to the relative size of each language collection and circulation statistics. The results would give some starting information about whether the language collections might be well balanced.

\section{Community Consultation is Essential to a Quality Multilingual Collection}

Community consultation provides important information (Lynch, 2015). In the consultation process, librarians must be aware that the concept of what a public library is and what it could provide can be a mystery to some newcomers (Steckman, 1998). Some countries or areas do not have libraries at all (Lynch, 2015). Some potential users may associate a library with books, especially serious academic books, but be unaware of other services (Lynch, 2015). Potential users may never think their local library could have a multilingual collection with books in their language. Part of the consultation process might need to be informing community members what does or could exist.

In Gothenburg City, Sweden, researchers initiated a study to determine the needs of the $21 \%$ of the city's population born outside of Sweden. The study consisted of 154 individuals participating in 14 focus groups (Atlestam et al., 2011). The focus groups contained a variety of people, with six of the groups consisting of people from the same cultural background, while the remaining groups were mixed (Atlestam et al., 2011). In total, people speaking 33 languages participated, from every continent except Australia. Information obtained from the focus groups was used in combination with statistics from the circulation and number of multilingual titles owned by the library. This gave a good picture of the needs and borrowing patterns of different language groups in the city (Atlestam et al., 2011).

A New Jersey library also tried connecting with its community to get feedback on their multilingual collection (Baker, 2012). The library staff started by approaching patrons who were browsing the stacks, but sometimes found a language barrier. More commonly, the patrons simply said everything was fine and seemed reluctant to give any negative feedback (Baker, 2012). The staff also tried forming focus groups, but found that there was little interest (Baker, 2012). What worked for their library was creating a brief paper 
survey and placing it inside the books at check out. Patrons were much more open about their opinions on paper rather than in person, perhaps because the survey was anonymous (Baker, 2012). For patrons whose first language is not English, takehome paper surveys may also be easier because there is unlimited time to think about and write answers, unlike a face-toface conversation, which requires immediate responses. Consulting the community about its needs and interests in a multilingual collection is very important and leads to positive results (Baker, 2012). However, what method works may vary by library or community and could require some experimentation.

\section{Libraries Must Define the Scope of their Multilingual Collection}

Before beginning to create or improve a multilingual collection, a library must decide how broad the collection will be. Each library must decide how many languages to actively collect (Rogers, 2003). For each language, the library should then decide on a level of service to provide. For example, the goal could be to provide a basic level of service, such as a small collection of books, or a more comprehensive service with a larger, more balanced collection, and translated library policies, forms, and handouts (Steckman, 1998). The degree of bilingualism and level of social integration of particular groups may impact their interest in service, and therefore the appropriate level of service (RUSA, 2007). A language community made up mostly of new immigrants may desire and benefit from a higher level of service than a language community made up of mainly bilingual second and third generation Canadians. However, bilingual, long-time residents may still strongly desire to read in their first language or use materials to teach the language to their children (Atlestam et al., 2011). In a multibranch system like Vancouver Public Library, for example, branches can be designated to hold language collections that represent their neighbourhoods (Vancouver Public Library, 2017). This practice can help concentrate smaller language collections in one area, while still providing access across a library system. Toronto Public Libraries is another example. They have material in over 40 languages (Toronto Public Library, 2017). As materials in so many languages would take up considerable space, spreading them out amongst the branches likely makes this more manageable.

\section{Multilingual Staff}

Employing staff who speak the major languages spoken in the community provides a significant advantage. It helps build trust and relationships between the community and the library (Lynch, 2015). Community members may be more comfortable asking multilingual staff for help (Atlestam et al., 2011). Multilingual staff members can also be a symbol of career success for members of a secondlanguage group and give youth or 
newcomers something to aspire to (Atlestam et al., 2011).

A librarian or staff member who speaks a particular language significantly helps with selecting and cataloguing books in that language (Baker, 2012). Richmond Public Library in British Columbia was fortunate to have two Chinese-speaking librarians, one of whom selected its non-fiction titles in person (Jang, 2003). Multilingual staff may have useful knowledge of book vendors and publishers in their ancestral country (Atlestam et al., 2011). They may also be aware of local bookstores and vendors, or have a sense of what authors or materials are popular in a certain community. Richmond Public Library (RPL) had great success and won awards for its highdemand services and collection for immigrants, especially for the Chinese community (Jang, 2003). At the time Jang's article was written, nearly $85 \%$ of area residents had a library card and Chinese materials accounted for $29 \%$ of the library's total circulation (Jang, 2003). Due to the size and quality of the Chinese-language collection, people from all over the BC Lower Mainland came to Richmond to borrow materials (Jang, 2003). This success is no doubt due to having the right staffing mix to understand the community's needs and make appropriate purchasing decisions. RPL acquired its Chinese materials from local suppliers, was able to get new materials frequently, and have them shelf-ready quickly (Jang, 2003). This set-up would have helped keep the collection fresh and current, thereby increasing its popularity.

\section{Best Practices When No Librarian Speaks a Community's Language}

Creating a successful multilingual collection is more challenging for library systems that do not possess staff capable of speaking and reading popular community languages (Baker, 2012). In this circumstance, librarians must be adaptable (Rogers, 2003). Librarians must tap into the community to find resources and remember that a librarian's greatest resource is often other librarians (Rogers, 2003). Rogers says, "Don't reinvent the wheel" (Rogers, 2003, p. 43). Librarians should talk to colleagues in other cities about their experiences developing collections and take any advice they can offer (Rogers, 2003). OCLC's WorldCat can allow librarians to see which other libraries hold selected titles (Rogers, 2003). Some libraries have set up formal collaborations to share ideas or materials. An example includes New Jersey's one-day workshops and MultiMAC, their statewide Multilingual Materials Acquisitions Centre (Steckman, 1998). MultiMAC built well-rounded collections that were available for bulk loans and also provided consultation, booklists, including ordering and cataloguing information, and information packets, including sample signage (Steckman, 1998). Other examples of collaboration are the Project ASIA centre, a collaboration among several California 
libraries with librarians trained in Chinese, Japanese, Vietnamese, and Korean language collection development (Schull, 1998), and Canada's former National Library Multilingual Biblioservice (Chilana, 2001). The Biblioservice used to facilitate exchanges of multilingual books between Canadian public library systems (Chilana, 2001). Collaborating and following the recommendations of other librarians can help librarians in smaller settings create and maintain multilingual collections more successfully.

\section{Translated Titles are Useful in a Multilingual Collection}

A special segment of a multilingual collection to consider is translated titles. Including quality books translated from English or other languages in a multilingual collection is recommended because readers look for these titles (Dali, 2010). In the case of translations from English, they can help multicultural readers connect to North American popular and literacy culture (Dali, 2010). Translations can be helpful to people practicing reading in their second language, or to people who cannot read fluently in English. Translated literature can open a window to the heart of a culture, connecting people to other places and societies (Dali, 2010).

\section{Sourcing Material for Multilingual Collections}

Once a library knows what materials to purchase, finding sources for these materials can be even more of a challenge
(Rogers, 2003). Libraries have often been passive receptors of the offerings of a small number of booksellers and publishers, and purchases have often been made based on what is available, not on the community's needs (Atlestam et al., 2011). Additionally, purchases have often reflected the needs and interests of the well-educated middleclass. When libraries lack linguistic or cultural competence, single sales companies can easily come to play a crucial role, meaning the collection could end up having an ideological bias or containing obsolete or unpopular material (Atlestam et al., 2011). Advice and collaboration with other librarians can help overcome these tendencies (Rogers, 2003). A local ethnic bookstore can be an extremely valuable resource, as can tapping into the local community to find vendors, or asking other librarians which vendors they use (Rogers, 2003).

A significant improvement is that materials in major languages can be acquired directly from online overseas suppliers ( $M a, 2015)$. This allows materials, including the most current and popular titles, to arrive within 2-3 weeks compared to the 3-6 months it took in the past (Ma, 2015). Amazon is increasingly offering multicultural literature in its original language ( $M a, 2015)$. This service improves the number of titles available and reduces the barriers of having to know vendors, navigate foreign language websites, currency, and arrange payment and shipping across international borders. 
For languages with limited written tradition, sourcing material can be especially challenging. Sometimes there is simply very little published in a language, such as Somali or Hmong (Lynch, 2015). The low volume of publishing in some languages may make it impossible to provide the same amount of material in all languages (RUSA, 2007). Some libraries collect English-language materials about a country's culture, history, and politics when little is available in its language (Lynch, 2015). If print materials are scarce, libraries can emphasize non-print materials like audio recordings and video, if possible (RUSA, 2007). However, these could be scarce as well. Vendors can be found in surprising places. For example, an American author found an excellent vendor of Somali materials in Stockholm, Sweden (Rogers, 2003). A country or region's political climate can play a role in the availability of materials (Rogers, 2003). For example, during the war in the former Yugoslavia it was impossible to get materials in some of the Slavic languages (Rogers, 2003).

\section{Cataloguing Multilingual Material}

Cataloguing multilingual material is another challenge for librarians. RUSA's Guidelines say that all materials should be catalogued in the original language and script (RUSA, 2007). One author suggests looking at OCLC's WorldCat to see how an item was catalogued by other libraries (Rogers, 2003). Another library system used a stand-alone Chinese cataloguing system for its Chinese collection (Jang, 2003). This library also used a modified Dewey Decimal classification system so cataloguing would take less time and the books would be shelf-ready faster (Jang, 2003). A librarian commented that, traditionally, librarians used dictionaries and lists of terms to catalogue multilingual material or referred to subject matter experts (Rubin, 2013). Now language identification and translation software can help greatly, although the technology is not perfect (Rubin, 2013). Cataloguing is important, especially in multi-branch collections, to allow users to see what materials they could potentially access. Greater Victoria Public Library recently fully catalogued most of its multilingual materials in an effort to improve the accessibility and quality of its collection ( $\mathrm{Ma}, 2015)$. A dissenting opinion, however, comes from Gothenburg City Library's study on multilingual materials. Their focus groups and library staff indicated that people looking for multilingual materials rarely used the catalogue (Atlestam et al., 2011). What was important to them was browsing items on the shelf. The authors expressed concern that the move to reduce or eliminate interlibrary deposits, which shared large groups of items between libraries, in favour of user-initiated single item loans, would disadvantage multilingual borrowers who overwhelming prefer to shelf browse (Atlestam et al., 2011). The facts that multilingual materials are not always catalogued well and that their users more often have limited 
experience using libraries could explain why shelf browsing is more prevalent in this population. However, if libraries catalogued their multilingual collections and provided signage and clear instructions on the benefits of using the catalogue, catalogue usage could potentially increase.

\section{Collection Maintenance}

Cataloguing a collection makes it easier to determine what the library owns and how frequently items are borrowed. Cataloguing also helps with collection maintenance, which should be done regularly (RUSA, 2007). Tracking circulation of books can help identify and potentially weed out books that are not being borrowed (Atlestam et al., 2011). Out of date and poor-condition materials can be discouraging to users and should be discarded (RUSA, 2007). When worn-out materials are still heavily used and relevant, preservation measures such as rebinding can be used to repair them (RUSA, 2007). Patrons in the Gothenburg City Library's study indicated that they wanted books that are new (Atlestam et al., 2011). This can pose a challenge as availability in some languages is limited and new items are not always available (Atlestam et al., 2011). Also, the appearance and quality of items produced in some countries, such as the paper type and bindings, may not be equal to the quality of items published in North America (RUSA, 2007). Weeding can be done in collaboration with interested library users as long as the selection principles of the library are clearly communicated. Otherwise, there is the risk of the collection being characterized by a single person or small group's preferences (Atlestam et al., 2011).

\section{Gothenburg: An Example of Multilingual Collection Evaluation}

Gothenburg City Libraries is an excellent example of a library that went through a substantial process of investigating what its multicultural patrons wanted and if its collection was meeting their needs. The study's authors spoke to people in focus groups, but also examined the circulation statistics from their multilingual collection to see what books were actually circulating (Atlestam et al., 2011). The collection was grouped by language and by type of book within each language. The categories used were children's materials, adult fiction, language learning material, non-fiction humanities and society, and everyday life handbooks. The authors calculated the percentage of times books of each category had circulated compared to their percentage of the total collection. This allowed them to see if certain categories were more popular, average, or unpopular. Unpopular categories would indicate a problem with the stock, such as being obsolete, needing weeding, or not being of interest to the community (Atlestam et al., 2011). The library found that there was a desire for easy-to-read material on their country, Sweden, and school textbooks at all levels and subjects in various languages. These reflected the desire of recent 
immigrants to learn about their new country and facilitate their understanding of concepts being learned in school by reading in their native languages. Parents wished for children's material in their native languages to help their children learn to read the language; however, circulation statistics showed that parents and children did not actually borrow this material very much, despite their stated desire. Nonfiction turned out to be more popular than expected, and was borrowed at a particularly high rate by men. What the authors called "everyday life handbooks," for example, books on cooking, raising children, driver handbooks, and computer manuals, were especially popular. These books were also considered very important by focus group participants, particularly to women and refugees (Atlestam et al., 2011). The study showed a difference between the habits of new immigrants, especially refugees, and people who had immigrated earlier. The newer immigrants needed materials for the integration process, and focused on useful materials. Longer-time residents used the library for leisure reading, primarily fiction books. Maintaining a connection with their native language was important to them. It was noted that fiction in Arabic tended not to circulate. The wrong type of items may have been purchased (Atlestam et al., 2011). Alternately, the circulation patterns could have been reflective of a group primarily made up of very new immigrants who were focused on non-fiction materials to meet their immediate integration needs.
Gothenburg City Library learned significant and useful information from their study. Atlestam et al. (2011) stated that one of the successful objectives was to create dialog with their multilingual users. Library users appreciated being asked for their views, and the importance of investing in dialog with residents was shown (Atlestam et al., 2011). The authors learned the library needed more practical materials like language-learning handbooks, school textbooks and everyday life materials. These were most important to the newest immigrants, who needed help establishing a new life in a new country. The authors felt it was important to prioritize the needs of this group (Atlestam et al., 2011). Focusing on basic materials is supported by the RUSA guidelines, which recommend providing literacy materials in the native languages of non-English speaking patrons (RUSA, 2007). The Gothenburg study authors also felt supporting leisure reading should be a responsibility of the library (Atlestam et al., 2011). They found that there is a need to continuously examine how the collections in different languages circulate to use in evidence-based decision making, including in relation to changing community demographics. Focus groups should be used to measure satisfaction. The authors stated that it is important to strive to find reliable sources for purchases. They said that it is not reasonable for every library to acquire the skills and networks for good purchasing in all languages, but that libraries should build networks and 
purchase channels at a national or regional level (Atlestam et al., 2011).

\section{Marketing Multilingual Collections}

Outreach and focus groups like what Gothenburg City Library used can also be a form of marketing. Participants can be informed about services at the same time that their opinions are being sought. Marketing is extremely important to the success of multilingual collections, which cannot be useful if no one knows about them. Marketing can take many forms. Focus group participants may tell others about their experiences at the library. Word of mouth like this is the best form of advertising (Rogers, 2003). For very new immigrants, an endorsement from someone they know well and trust is extremely valuable as they are navigating totally unfamiliar places and cultures and need courage to try things out (Cowles, 2013). RUSA guidelines say that the multilingual collection must be visible and accessible to the community (RUSA, 2007). They recommend displaying highly-visible directional signage in the community's languages, and also providing multilingual forms, notices, and information pamphlets (RUSA, 2007). RUSA also recommends providing outreach services in locations familiar to the community, such as community centres, and participating in local festivals. Multilingual library skills instruction should be provided as needed (RUSA, 2007). Another effective marketing method can be arranging for classrooms of children to visit because they will tell their parents what the library offers (Rogers, 2003).

Libraries should not be afraid to consider whether the physical presence of their collection is welcoming to users. One library changed the set-up of its ESL section, using descriptive signage such as "citizenship," "grammar," and "pronunciation," because they felt that ESL users may be more hesitant to ask for help and that would be easier for them to navigate than regular Dewey Decimal shelving (Baker, 2012, p. 35).

\section{Web Presence is Important for Multilingual Collections}

A good web presence is important for marketing a multilingual collection. RUSA guidelines say that libraries should have versions of their website in the different preferred languages of library users (RUSA, 2007). Obviously, having websites in each language becomes much more difficult in a city where many languages are spoken, as opposed to a city with only one or two languages. Toronto Public Libraries and Vancouver Public Libraries have webpages that indicate which libraries house collections in particular languages (Toronto Public Library, 2017; Vancouver Public Library, 2017). Greater Victoria Public Library promotes its multilingual collection through an information page in its website (Ma, 2015). This library has also posted lists of materials it owns on communities' eforums, such as a list of children's 
audiobooks in Chinese or adult books in German (Ma, 2015).

\section{Collections and Services are Mutually Beneficial}

Building quality multilingual collections is only one way for a library to provide good service to its community. Other factors, such as providing good programming, are also important. Services can be mutually beneficial as the multilingual collection can be advertised to people who are coming in for programming and vice versa (Ma, 2015). One library found that long-term programs were better than one-time events for increasing attendance at the library (Lynch, 2015). Other creative ways to connect include maintaining a display case that showcases items from the home countries of community members (Baker, 2012). Library patrons brought in pottery, traditional clothing, art, and more, which has become a popular way to learn about other countries (Baker, 2012). This library also created a "translation aid" or flip chart of phrases in different languages and translations, which allowed community members to have basic conversations with library staff (Baker, 2012). It was warmly received by community members, who seemed genuinely pleased that the library had made an effort to assist and welcome them (Baker, 2012).

\section{Staff Training and Skills Support Multilingual Collections and Patrons}

Staff training is an important part of serving a multilingual community and supporting the multilingual collection. Library staff working with populations with limited English or French should be multilingual to provide effective service (RUSA, 2007). Language ability has become a pressing issue, as the need for multilingual librarians has outpaced the supply, especially in large, urban library systems (Schull, 1998). Continuing education programs or staff development should promote sensitivity and cultural, ethnic, and linguistic awareness (RUSA, 2007). Library staff with expertise in language and cultures should share their expertise with others and should be recognized and compensated for these valuable abilities (RUSA, 2007). Masters of Library and Information Studies (MLIS) programs should advertise the need for multilingual and multicultural librarians and actively recruit students from diverse backgrounds (RUSA, 2007). Courses that deal with the issues involved in serving a culturally- and linguistically-diverse society should be included in MLIS and Library Technician programs (Chilana, 2001). Newcomers to Canada who have library training in their home country should be provided with the opportunity to take training and gain exposure to Canadian libraries in order to successfully gain employment (Chilana, 2001). As well as benefitting these individuals, helping newcomer librarians gain employment 
would increase the diversity of Canada's librarians and library staff. Toronto Public Library has an excellent example of a very multicultural staff team who are able to speak almost all of the 40 languages available in their collection (Rogers, 2003).

\section{Conclusion}

A quality multilingual collection is an important part of providing appropriate library service to a diverse community. As we are a multicultural society, it is important that libraries strive to provide equitable service and access to information for all (Dilevko \& Dali, 2002). Although it appears that many libraries consider Indigenous languages separately from their multilingual collections, much of the information that relates to building multilingual collections could also apply to the Indigenous language communities. It can take time and resources to build, market, and maintain a multilingual collection, especially if the library does not have staff who can speak and read all of the languages (Baker, 2012). Libraries who can recruit multilingual staff have a significant advantage, and those staff should be encouraged and appreciated for sharing their skills (Chilana, 2001). However, with or without multilingual staff, working with the community, getting to know its needs, collaborating with other libraries to share ideas and information, identifying good vendors, cataloguing and maintaining the collection, marketing it appropriately, and providing staff training can help a library be successful. Over time and through this process, a library can build up experience serving its multilingual community well. Working with other libraries and librarians and sharing knowledge should be stressed as a key way to efficiently serve diverse communities and build multilingual collections. Although it can be challenging, successfully engaging and serving a multilingual community brings with it great rewards, and will be appreciated.

\section{References}

Atlestam, I., Brunnstrm, A., \& Myhre, R. (2011). Collection development for immigrants - what to purchase, and why? Findings in Gothenburg, Sweden. IFLA Journal, 37(1), 69-79. doi:10.1177/0340035210397308

Baker, K. (2012). Meeting the needs of diverse communities. Public Libraries, 51(5), 34-35.

Chilana, R. (2001). Delivering multilingual services in public libraries in British Columbia: A case study of the Fraser Valley Regional Library. PNLA Quarterly, 65(3), 18-20.

Cowles, D. (2013). The ESL patron perspective. Alki, 29(1), 8-9.

Dali, K. (2010). Readers' advisory in public libraries and translated fiction. Reference Librarian, 51(3), 175188.

doi:10.1080/02763871003733430 
Dilevko, J., \& Dali, K. (2002). The challenge of building multilingual collections in Canadian public libraries. Library Resources \& Technical Services, 46(4), 116-137.

Greater Victoria Public Library. (2017). Francais \& World Languages.

Retrieved from https://www.gvpl.ca/read/francaisworld-languages/

Jang, W. (2003). Multilingual services at Richmond Public Library. Feliciter, 49(3), 158-160.

Lynch, G. H. (2015). A world of opportunity. School Library Journal, 61(4), 1.

Ma, A. (2015). What Do We Provide for Multicultural Patrons? The Impact of Collection Development on Readers' Advisory for Multicultural Patrons. Retrieved from BCLA Reader's Advisory Group: What are you reading?: https://whatareyoureadingblog.co m/tag/multilingual-collections/

Rogers, M. (2003). Serving up world languages. Library Journal, 128(11), 42-44.

Rubin, V. (2013). How is your libraries dealing with foreign language resources (in terms of information organization, access, and curation)? Retrieved from Research Gate: https://www.researchgate.net/post /How_is_your_libraries_dealing_wit h_foreign_language_resources_in_t erms_of_information_organization_ access_and_curation

RUSA. (2007). Guidelines for the development and promotion of multilingual collections and services. Reference \& User Services Quarterly, 47(2), 198-200.

Schull, D. D. (1998). Innovating to serve the global village: Thoughts about multilingual and multicultural services. Reference Services Review, 26(2), 59-63.

Skrzeszewski, S. (1993). The Southern Ontario multilingual pool: $A$ model for co-operative library service development. Audiovisual Librarian, 19, 129-136.

Steckman, B. (1998). Library services to a linguistically diverse community: $A$ workshop report from New Jersey. Reference Services Review, 26(2), 57-59.

Toronto Public Library. (2017). Material in your language. Retrieved from http://www.torontopubliclibrary.ca /books-video-music/yourlanguage/ 
Vancouver Public Library. (2017). World languages. Retrieved from https://www.vpl.ca/borrowing/worl d-languages 